\title{
Localization of the Mental Foramen Through Digital Panoramic Radiographs in a Chilean Population
}

\author{
Localización del Foramen Mental a Través de Radiografías \\ Panorámicas Digitales en una Población Chilena
}

\author{
Ramón Fuentes ${ }^{1,2}$; Tania Flores ${ }^{1,2}$; Fernando Dias ${ }^{1,2}$; Constanza Farfán ${ }^{3}$; Nicolás Astete ${ }^{3}$; Pablo Navarro ${ }^{2}$ \& Alain Arias ${ }^{1,2,4}$
}

FUENTES, R.; FLORES, T.; DIAS, F.; FARFÁN, C.; ASTETE, N.; NAVARRO, P. \& ARIAS, A. Localization of the mental foramen through digital panoramic radiographs in a Chilean population. Int. J. Morphol., 35(4):1309-1315, 2017.

SUMMARY: The purpose of the current research was to describe the location of mental foramen (MF) through digital panoramic radiographs in a Chilean population sample. A cross sectional study was carried out in which 500 radiographs taken at a university clinic in Temuco, Chile, were analyzed. Exclusion criteria were applied and the radiographs were analyzed by two previously calibrated examiners. The antero-posterior and supero-inferior positions of the MF were established in relation to longitudinal axes of premolars and the height of their apices, respectively. The distances from the center of the MF to the inferior margin of the mandible, the midline and the height of the dental apices were measured. In total, 163 radiographs were analyzed ( 93 female, 70 male). On both left and right sides, the MF was most commonly found between the longitudinal axes of premolars (58.49\% and $65.43 \%)$ and below of the apices $(94.34 \%$ and $95.68 \%$ ), with no significant differences for sex and age. On the right side the mean distance to the inferior margin of the mandible (D1) was $11.87 \pm 1.46 \mathrm{~mm}$; to the midline (D2) it was $24.46 \pm 2.99 \mathrm{~mm}$ and to the height of the apices (D3) it was $5.03 \pm 8.44 \mathrm{~mm}$. On the left side the same distances were $11.98 \pm 1.62 \mathrm{~mm}, 25.85 \pm 2.87 \mathrm{~mm}$ and $4.09 \pm 2.21 \mathrm{~mm}$ respectively. In conclusions, the distances measured from the MF to anatomical landmarks are smaller in women, however significant differences were only found for D1 (right and left sides) and D3 (left side). D2 was the only distance found to diminish with age (left side).

KEY WORDS: Mental Foramen; Digital Panoramic Radiographs; Morphometry; Chilean population; Localization.

\section{INTRODUCTIÓN}

The mental foramen (MF) is a small foramen located in the antero-lateral surface of the body of the mandible (Voljevica et al., 2015). Its position is commonly described as being below the second premolar and close to the inferior margin of the mandible (Afkhami et al., 2013), although some reports show variations in its location associated with ethnic group, sex (Afkhami et al.; Chkoura \& El Wady, 2013) and age (Ajmal, 2014). The MF is not always symmetrical in the same individual (Gangotri et al., 2011) and it is normally single, although the existence of double and even multiple foramina has been shown (Al-Khateeb et al., 2007; Al-Talabani et al., 2008). The mental nerve (MN) is a terminal branch of the inferior alveolar nerve (Haghanifar \& Rokouei, 2009); it passes through this foramen and innervates the lower lip, the vestibule and the gum from mesial of the first molar forwards (Talabani et al.; Chkoura
\& El Wady). The MF and observation of the MN are anatomically important, and must be considered during possible traumas and in maxillofacial surgical procedures such as implants, and periapical and orthognathic surgery (Afkhami et al.). Precise knowledge of the variations in the shape, size and position of the MF is therefore very useful (Voljevica et al.). Together with the mandibular canal, the MF is also an important reference for forensic analysis (Ajmal) and oral pathology (Chkoura \& El Wady).

Panoramic radiograph are often used to study the MF (Afkhami et al.; Al-Talabani et al.; Fuentes et al., 2014; Gangotri et al.; Haghanifar \& Rokouei; Shah et al., 2013; Shibli et al., 2012) since they offer a good diagnostic image for an immediate view of the patient's whole maxillofacial system (Fuentes et al.; Mohamed et al., 2016), including

\footnotetext{
${ }^{1}$ Department of Integral Adult Dentistry, Dental School, Universidad de La Frontera, Temuco, Chile.

${ }^{2}$ Research Center in Dental Sciences (CICO), Dental School, Universidad de La Frontera, Chile.

${ }^{3}$ Master's Program in Dentistry, Dental School, Universidad de La Frontera, Chile.

${ }^{4}$ Universidad Adventista de Chile, Chillán, Chile.
} 
teeth, jaw and temporomandibular joint (Afkhami et al.). Panoramic radiography is considered a standard examination for planning various treatments, including implants (Pyun et al., 2013); the image quality can be improved by using digital format (Afkhami et al.). This examination, commonly used in clinical dental practice, is much more accessible than other three-dimensional image exams, such as cone beam computerized tomography, which although more precise requires greater expertise, involves higher costs and takes longer to analyze.

The main objective of this study was to describe the location of the MF in relation to the adjacent teeth, and its distance from reference points which are easily identifiable in clinical practice. For this work we used digital panoramic radiograph from a sample Chilean population.

\section{MATERIAL AND METHOD}

Cross sectional study in which 500 radiograph (ratio 1:1) taken in March 2015 in the Dental Teaching Clinic (CODA) of the Dental School of Universidad de La Frontera, Temuco, Chile were examined. The radiographs were taken using standard technique with a PAX-400C orthopantomograph (VATECH, Korea, 2010). This study was approved by the Scientific Ethics Committee (CEC) of Universidad de La Frontera, Chile (Folio no. 015/2014).
We excluded radiograph of patients aged less than 21 years old and those with deficient image quality (distortion or contrast alteration). Cases also excluded were those showing evidence of pathologies affecting visibility in the study zone, teeth with incomplete or abnormal development, impacted or clearly malpositioned teeth, partial edentulism in the canine, premolar and/or molar region (to the 2nd molar forward) and evidence of orthognathic surgery, orthodontics or trauma. These criteria were applied in order to obtain a normal sample of patients without anatomic alterations.

The measurements were taken using AutoCAD software (version 2006; Autodesk, San Rafael, CA, USA), which allowed the measure of straight lines and angles between the different anatomical reference points in the radiograph. The size of each radiograph was adjusted in the measurement software following the parameters indicated by the software of the orthopantomograph. All digital panoramic radiographs were projected on a 29" LED monitor (LG, model 29UM67) with a resolution of 2560x1080 pixels and were analyzed by two previously calibrated examiners. The presence and position of the MF visible on both sides of the mandible (right and left) were determined independently for each radiograph. To describe their position, the classification described by Fuentes et al., was used, summarized in Table I and Fig. 1. Then the distance from the MF to certain anatomical reference points was determined. To do this a line was drawn parallel to the horizon and tangential to the inferior margin of the body of the mandible (L1) and a second

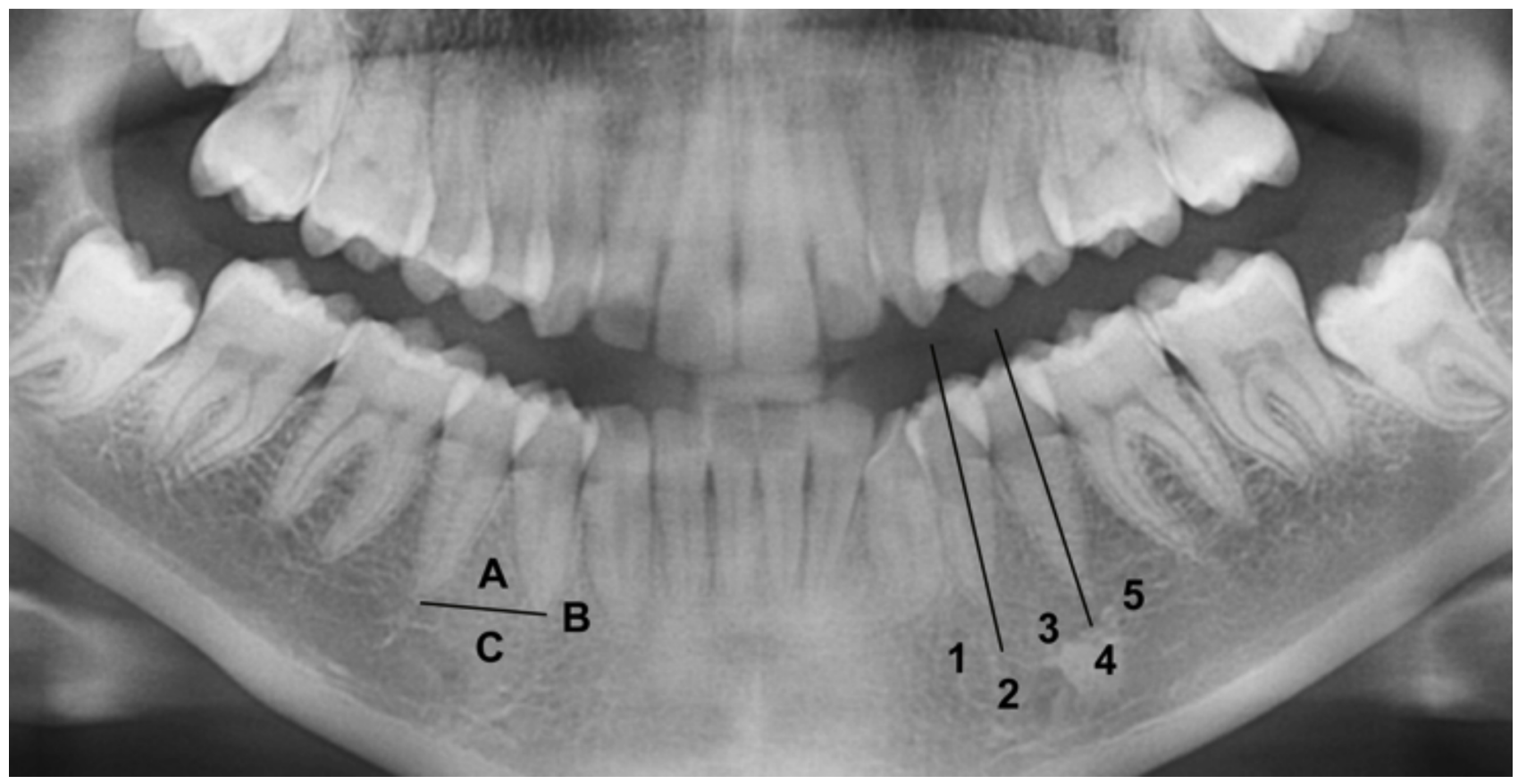

Fig. 1. The antero-posterior and supero-inferior positions of the MF were defined by classification in relation to the longitudinal axes of the mandibular premolars and the location of the dental apices respectively. 


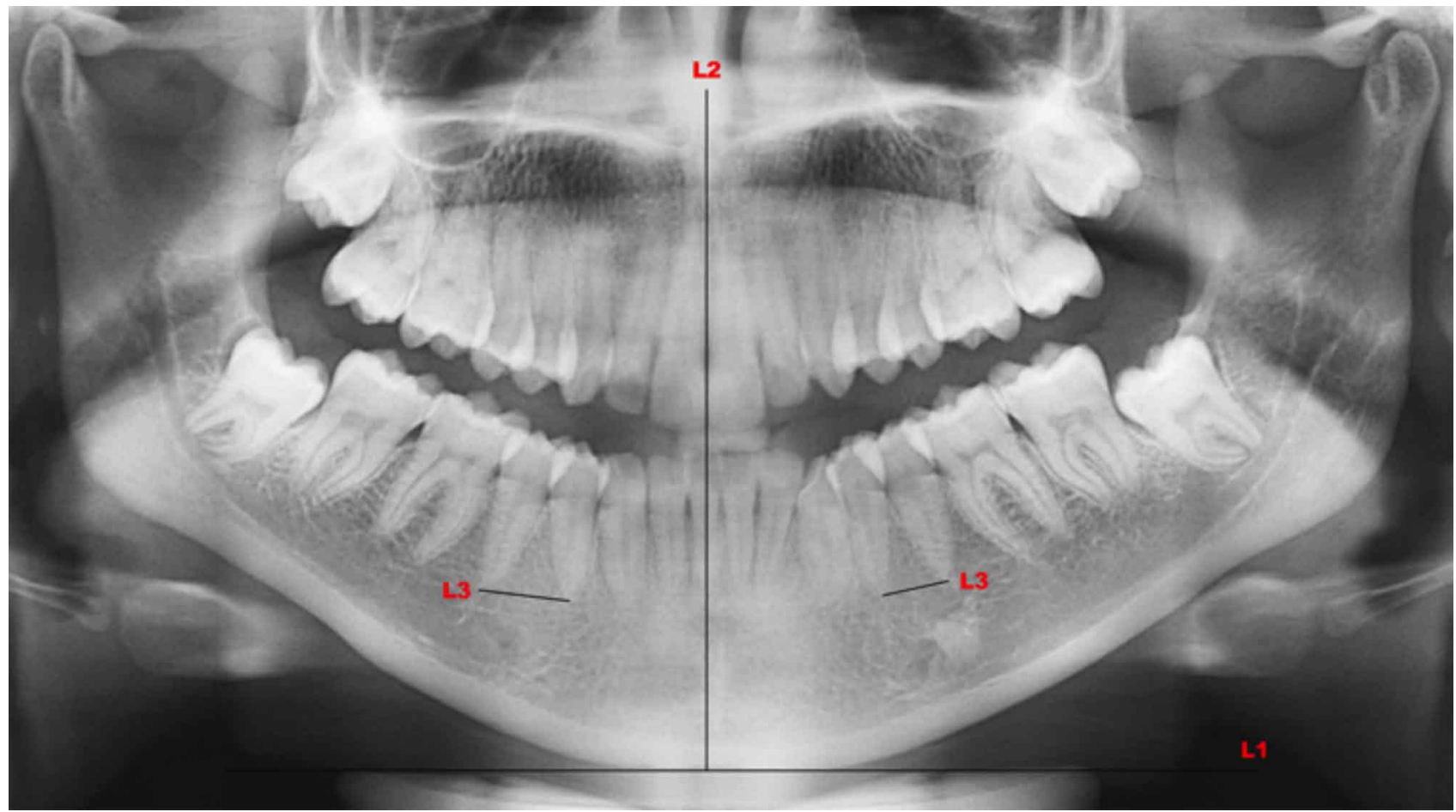

Fig. 2. Reference lines drawn on the digital panoramic radiograph and used to establish the posterior measurements. L1 is horizontal, and tangential to the inferior margin of the mandible; L2 is the midline which passes through the anterior nasal spine and is perpendicular to L1; L3 is the line joining the apices of the teeth adjacent to the MF.

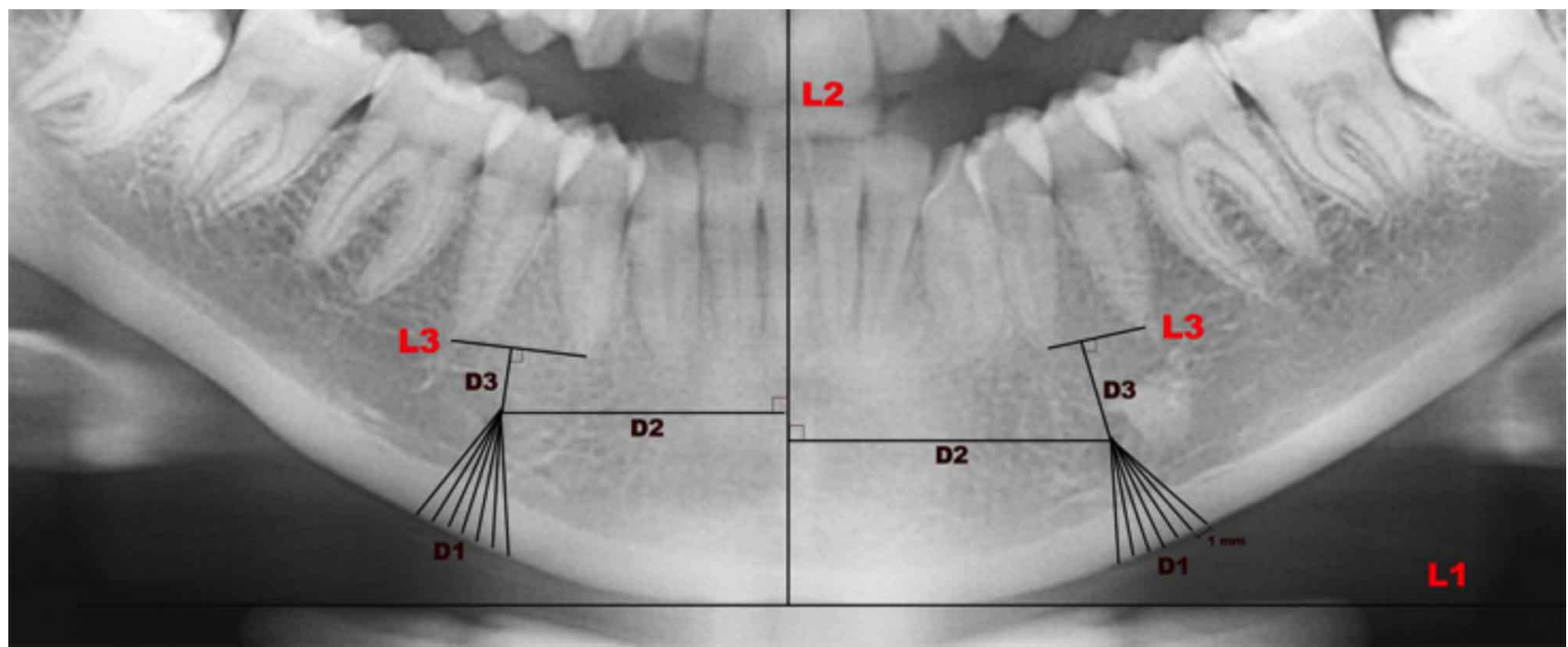

Fig. 3. Diagram of measurements taken with the AutoCad software on the digital panoramic radiograph. D1 is the shortest distance between the MF and the inferior margin of the mandible; it is found by tracing straight radii from the center of the MF to points every 1 $\mathrm{mm}$ along the inferior margin of the mandible. D2 is the shortest distance between the MF and the midline and is perpendicular to L2. D3 is the shortest distance between the MF and the height of the apices and is perpendicular to L3.

line (L2) through the midline determined by the anterior nasal spine and perpendicular to L1 (Fig. 2). A third line (L3) was drawn to join the anatomical apices of the first and second premolars adjacent to the MF (Fig. 2). The following measurements were then taken:
D1: minimum distance between the centre of the MF and the inferior margin of the mandible (Fig. 3). This minimum distance was found by tracing straight radii from the centre of the MF to points every $1 \mathrm{~mm}$ along the inferior margin of the mandible. 
D2: minimum distance between the centre of the MF and the midline (L2) i.e. perpendicular to the midline (Fig. 3).

D3: minimum distance between the center of the MF and the line joining the dental apices (L3) i.e. perpendicular to that line (Fig. 3). For the cases of MF in the antero-posterior positions 1, 2, 4 and 5 (Table I and Fig. 1) in which a straight line could not be drawn perpendicular to L3, the latter was extended to mesial or distal (according to the case) in order to obtain a perpendicular to the center of the MF.

In order to determine inter-operator agreement, the intraclass correlation coefficient (ICC) was calculated to measure the distances between MF and anatomical landmarks and a kappa statistic (k) was used to identify the relation of the MF to adjacent structures. Both examiners separately analyzed 50 digital panoramic radiographs. The data were recorded separately for each MF (right and left) identified in the radiograph. Statistical analysis was carried out using SPSS/PC software (20.0, Chicago, IL). For descriptive statistics we used mean \pm standard deviation. The homogeneity of variance was determined by Levene's Test; the T-test for independent samples, chi square test and ANOVA was applied. The level of significance used in all statistical analyses was $\mathrm{p} \leq 0.05$.

\section{RESULTS}

The entire study consisted of 500 digital panoramic radiograph. Once the exclusion criteria had been applied, 163 images were analyzed: 93 women and 70 men, mean age $34.65 \pm 11.73$ years. A total of $321 \mathrm{MF}$ were identified and analyzed, 159 on the right side and 162 on the left. The ICC in the inter-operator concordance analysis was $99 \%$ (very good concordance), while the $\mathrm{k}$ index was $100 \%$.

Table I. Classification of the position of the MF relative to the height of the dental apices and the longitudinal axes of the first and second mandibular premolar.

\begin{tabular}{lll}
\hline & 1 & Anterior of the longitudinal axis of the first mandibular premolar \\
Antero-Posterior & 2 & In line with the longitudinal axis of the first mandibular premolar \\
& 3 & Between the longitudinal axes of the first and second mandibular premolars \\
4 & In line with the longitudinal axis of the second mandibular premolar \\
& 5 & Posterior of the longitudinal axis of the second mandibular premolar \\
\hline Supero-Inferior & A & Coronal of the apex of the teeth directly related with the MF \\
& B & At the same level with the apex of the teeth directly related with the MF \\
& C & Apical of the apex of the teeth directly related with the MF
\end{tabular}

Table II. Frequency and percentage of the antero-posterior and supero-inferior positions of the MF on the right side by sex and age band. The $\mathrm{x} 2$ test was used to detect statistical differences between the variables.

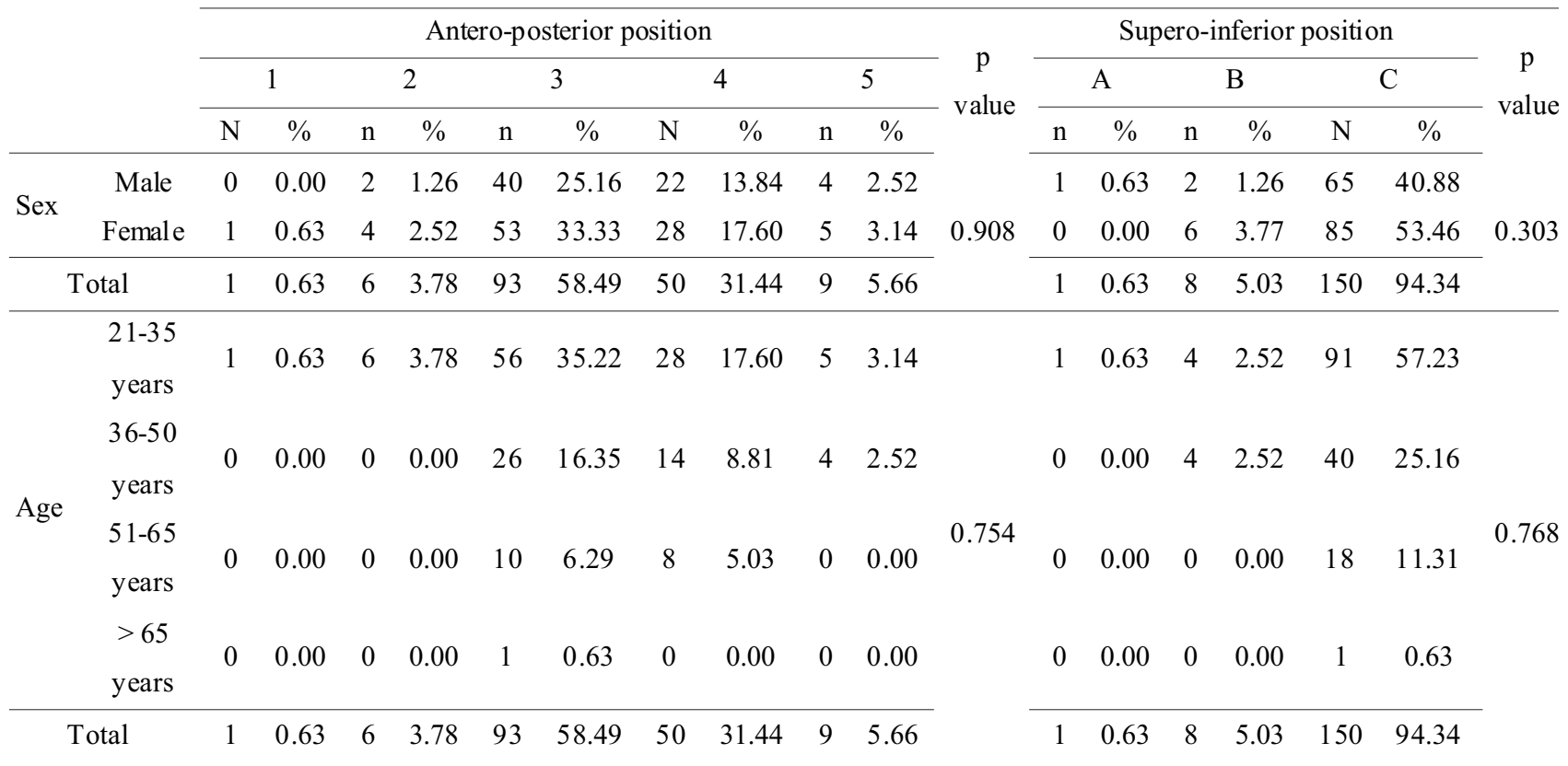


The most common antero-posterior position of the MF on the right and left sides (Tables II and III respectively) was between the longitudinal axes of the first and second premolars, with $58.49 \%(\mathrm{n}=93)$ and $65.43 \%(\mathrm{n}=106)$ respectively (position 3 in Table I); there were no statistical differences according to sex $(\mathrm{p}=0.908$ and $\mathrm{p}=0.291$ ) or age $(\mathrm{p}=0.754$ and $\mathrm{p}=0.975$ ). For the supero-inferior position, both on the right and the left side (Tables II and III respectively), the MF was located apical of the apex of the adjacent teeth in $94.34 \%(\mathrm{n}=150)$ and $95.68 \%(\mathrm{n}=155)$ respectively (position $\mathrm{C}$ in Table I), without significant differences according to sex $(\mathrm{p}=0.303$ and $\mathrm{p}=0.460)$ or age $(\mathrm{p}=0.768$ and $\mathrm{p}=0.951$ ).
For the distances measured from the center of the MF to adjacent anatomical reference points, on the right side the mean distance to the inferior margin of the mandible (D1) was $11.87 \pm 1.46 \mathrm{~mm}$; to the midline (D2) it was $24.46 \pm 2.99 \mathrm{~mm}$ and to the height of the apices (D3) it was $5.03 \pm 8.44 \mathrm{~mm}$. On the left side the same distances were $11.98 \pm 1.62 \mathrm{~mm}, 25.85 \pm 2.87 \mathrm{~mm}$ and $4.09 \pm 2.21 \mathrm{~mm}$ respectively. Table IV shows measurements D1, D2 and D3 from the MF on each side (right and left), by sex and age. D1 was longer in men than women on both the right side $(\mathrm{p}=0.000)$ and the left $(\mathrm{p}=0.000)$, while $\mathrm{D} 3$ was only longer on the left side ( $\mathrm{p}=0.004)$. D2 diminished with advancing age on the left side only $(\mathrm{p}=0.001)$.

Table III. Frequency and percentage of the antero-posterior and supero-inferior position of the MF on the left side by sex and age band. The $\mathrm{x}^{2}$ test was used to detect statistical differences between the variables.

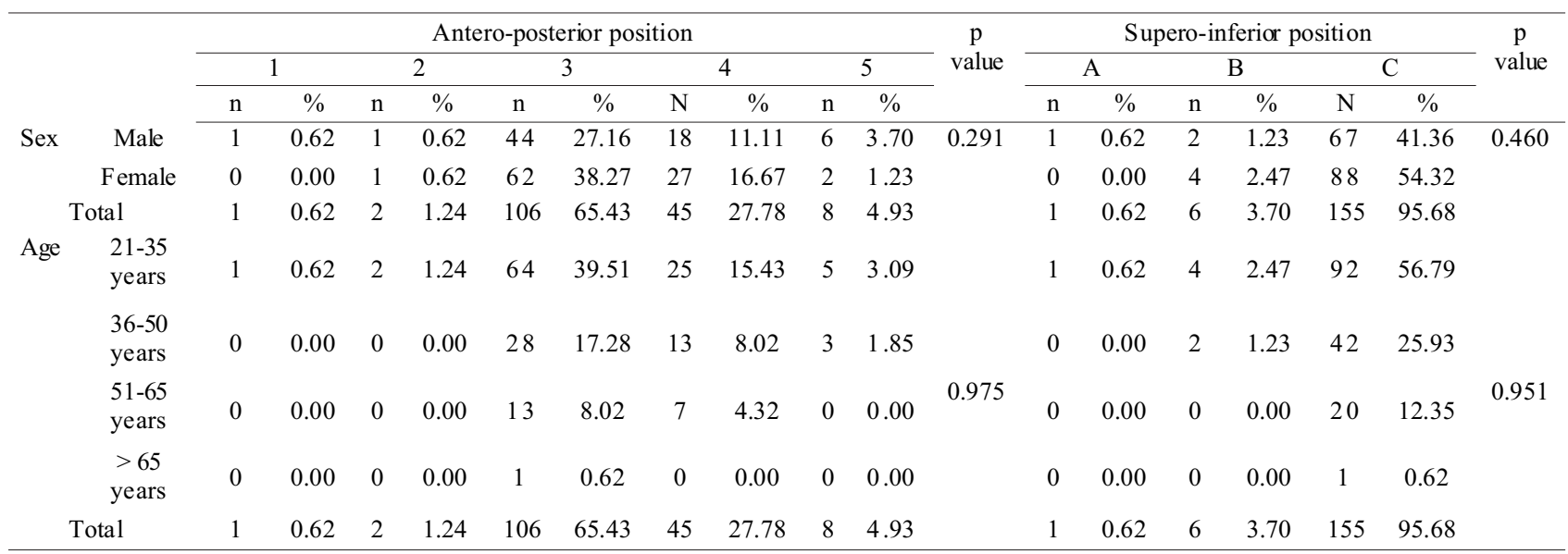

Table IV. Distances (mean \pm standard deviation) measured from the center of the MF to the inferior margin of the mandible, midline and height of the corresponding dental apices, for each side by sex and age band. The T-test for independent samples and ANOVA was used to detect statistical differences between variables.

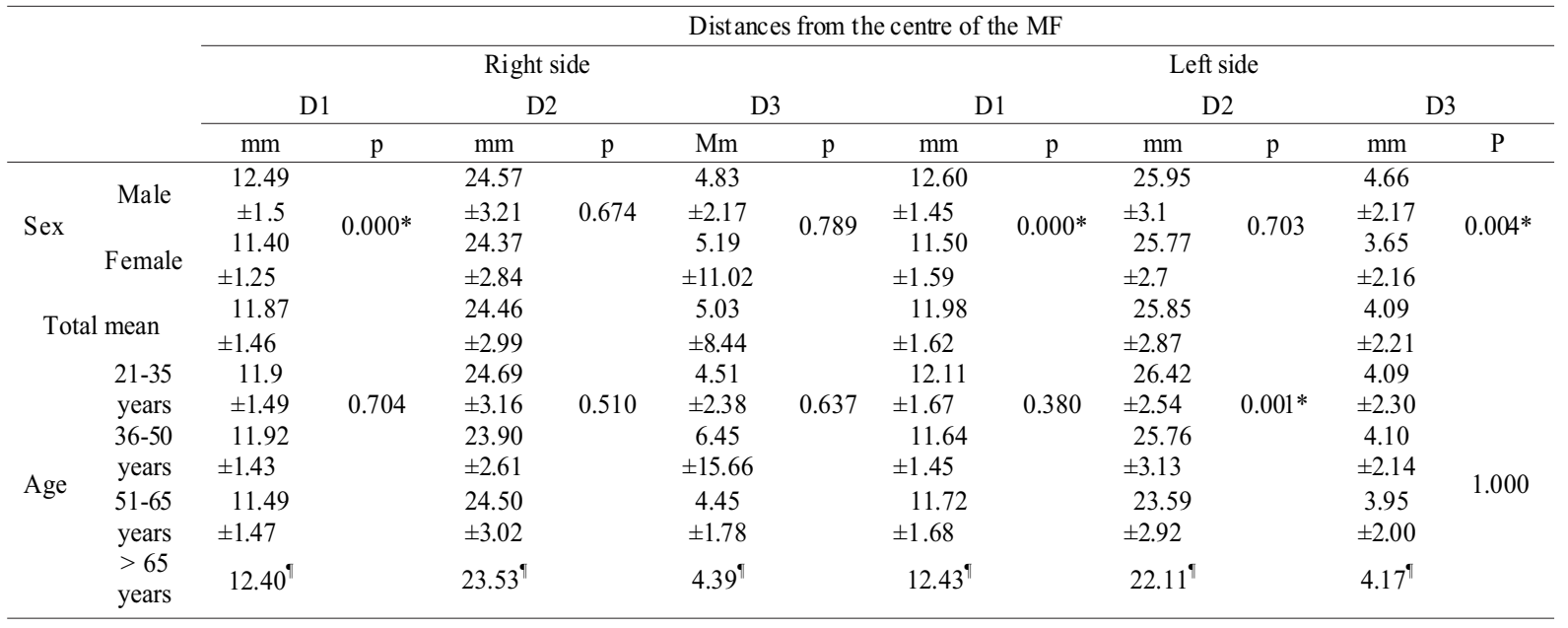

* Statistically significant difference

II Measured in only one case $(\mathrm{n}=1)$. These values were discarded for the statistical analysis 


\section{DISCUSSION}

The location of the MF has been widely studied using various methods. In our study with digital panoramic radiograph, we found that its most frequent position is between the first and second premolar $(58.49 \%$ on the right side and $65.43 \%$ on the left), similar to the findings reported by other authors such as Al-Khateeb et al. (47\%), El-Anwar et al. (2016) (78.3\%), Von Arx et al. (2013) (56\%) and Currie et al. (2016) (51\%), who used the same type of examination. Other studies contributed different data and aspects in the location of the MF, for example Gungor et al. (2017), who related the position of the MF between the first and second premolar with the female sex, or studies such as Thakare et al. (2016), Chong et al. (2017), al Jasser \& Nwoku (1998) and Ngeow \& Yuzawati (2003) who found a higher frequency of the MF close to the second premolar.

The analysis of the supero-inferior position of the MF in our study agrees with other reports (Al-Khateeb et al.; AlShayyab et al., 2016; Chkoura \& El Wady; Von Arx et al.), which frequently locate it below the level of the dental apices of the adjacent teeth $(94.34 \%$ on the right side and $95.68 \%$ on the left). It has been reported that this location may vary with age (Mohamed et al.) and sex (Al-Talabani et al.; Gungor et al.; Mohamed et al.). In our study we found no statistically significant differences in the supero-inferior position of the MF according to sex, in agreement with Al-Anwar et al., Thakare et al., Al-Khateeb et al., Al-Shayyab et al. and Chkoura \& El Wady.

Measurement of distances from the MF to anatomical reference points is a widely-used method for estimating its position as accurately as possible (Al-Talabani et al.; Mohamed et al.; Thakare et al.). In this study we present different measurements which were defined in an earlier report (Fuentes et al.) carried out with conventional panoramic radiography. In our analysis of digital radiograph, the measurements obtained were smaller than those reported previously from conventional examinations (Fuentes et al.), both for the distance from the MF to the inferior margin of the mandible or D1 (11.87 \pm 1.46 $\mathrm{mm} \mathrm{v} / \mathrm{s} 16.6 \pm 2.5 \mathrm{~mm}$ on the right side and $11.98 \pm 1.62 \mathrm{~mm}$ v/ s $17.1 \pm 2.3 \mathrm{~mm}$ on the left side) and for the distance from the MF to the midline or D2 $(24.46 \pm 2.99 \mathrm{~mm}$ v/s $35.3 \pm 5.1 \mathrm{~mm}$ on the right side and $25.85 \pm 2.87 \mathrm{~mm}$ v/s $35.6 \pm 5.4 \mathrm{~mm}$ on the left side). In our study, statistically significant differences by sex were observed only for D1 on the right and left sides and D3 on the right side (smaller measurement in women); this agrees with Gungor et al., who used cone beam computerized tomography in their analysis. We also observed statistically significant differences by age only for D2 on the left side; the distance diminished with advancing age.
The MF is an important anatomical reference which must be considered during some surgical procedures. Through analysis of digital panoramic radiography we determined that it is most frequently located between the first and second premolar, on both the right side $(58.49 \%)$ and the left $(65.43 \%)$, and below the height of the adjacent dental apices on both the right side $(94.34 \%)$ and the left $(95.68 \%)$. In general, the distances measured from the center of the MF to anatomical references (inferior margin of the mandible, height of the apices or midline) are smaller in women, however significant differences were only found for D1 (right and left sides) and D3 (left side). D2 was the only distance found to diminish with age (left side).

ACKNOWLEDGMENTS. Financial support (partially) by the Office of Research, Universidad de La Frontera, Chile.

FUENTES, R.; FLORES, T.; DIAS, F.; FARFÁN, C.; ASTETE, N.; NAVARRO, P. \& ARIAS, A. Localización del foramen mental a través de radiografías panorámicas digitales en una población chilena. Int. J. Morphol., 35(4):1309-1315, 2017.

RESUMEN: El objetivo de este estudio fue describir la localización del foramen mental (FM) a través de radiografías panorámicas digitales en una población chilena. Se realizó un estudio de corte transversal en el cual se analizaron 500 radiografías tomadas en una clínica universitaria de la ciudad de Temuco. Se aplicaron criterios de exclusión y las radiografías incluidas fueron analizadas por dos examinadores previamente calibrados. La posición antero-posterior y supero-inferior del FM se estableció de acuerdo a los ejes longitudinales de los premolares y la altura de sus ápices respectivamente. También se midió la distancia desde el centro del FM hasta el borde inferior de la mandíbula, hasta la línea media y hasta la altura de los ápices dentarios. En total, 163 radiografías fueron analizadas (93 mujeres, 70 hombres). Tanto para el lado derecho como izquierdo, la ubicación más frecuente del FM fue entre los ejes longitudinales de los premolares $(58,49$ $\%$ y $65,43 \%$ ) y debajo de los ápices $(94,34 \%$ y 96,68 \%), sin diferencias significativas por sexo y edad. En el lado derecho la distancia promedio desde el FM hasta el borde inferior de la mandíbula (o D1) fue $11,87 \pm 1,46 \mathrm{~mm}$; a la línea media (o D2) fue $24,46 \pm 2,99 \mathrm{~mm}$ y a la altura de los ápices fue de 5,03 $\pm 8,44 \mathrm{~mm}$. En el lado izquierdo el promedio de las mismas distancias fueron $11,98 \pm 1,62 \mathrm{~mm}, 25,85 \pm 2,87 \mathrm{~mm}$ y 4,09 $\pm 2,21 \mathrm{~mm}$ respectivamente. En conclusión, las distancias medidas desde el centro del FM hacia referencias anatómicas son menores en mujeres, sin embargo solo se encontraron diferencias significativas para D1 (en el lado derecho e izquierdo) y D3 (en el lado izquierdo). D2 fue la única distancia encontrada que disminuye con la edad (lado izquierdo).

PALABRAS CLAVE: Foramen mental; Radiografías panorámicas digitales; Morfometría; Población chilena; Localización. 


\section{REFERENCES}

Afkhami, F.; Haraji, A. \& Boostani, H.R. Radiographic localization of the Mental Foramen and Mandibular Canal. J. Dent. (Tehran), 10(5):43642, 2013.

Ajmal, M. Evaluation of Mental Foramen position from panoramic dental radiographs. J. Contemp. Dent. Pract., 15(4):399-402, 2014.

Al Jasser, N. M. \& Nwoku, A.L. Radiographic study of the mental foramen in a selected Saudi population. Dentomaxillofac. Radiol., 27(6):341-3, 1998.

Al-Khateeb, T.; Al-Hadi Hamasha, A. \& Ababneh, K. T. Position of the Mental Foramen in a northern regional Jordanian population. Surg. Radiol. Anat., 29(3):231-7, 2007.

Al-Shayyab, M.; Alsoleihat, F.; Dar-Odeh, N.; Ryalat, S. \& Baqain, Z. The Mental Foramen II: radiographic study of the superior-inferior position, appearance and accessory foramina in Iraqi population. Int. J. Morphol., 34(1):310-9, 2016.

Al-Talabani, N.; Gataa, I. S. \& Jaff, K. Precise computer-based localization of the Mental Foramen on panoramic radiographs in a Kurdish population. Oral. Radiol., 24:59-63, 2008.

Chkoura, A. \& El Wady, W. Position of the Mental Foramen in a Moroccan population: A radiographic study. Imaging. Sci. Dent., 43(2):71-5, 2013.

Chong, B. S.; Gohil, K.; Pawar, R. \& Makdissi, J. Anatomical relationship between Mental Foramen, mandibular teeth and risk of nerve injury with endodontic treatment. Clin. Oral. Investig., 21(1):381-7, 2017.

Currie, C.C.; Meechan, J. G.; Whitworth, J. M.; Carr, A. \& Corbett, I. P. Determination of the Mental Foramen position in dental radiographs in 18-30 year olds. Dentomaxillofac. Radiol., 45(1):20150195, 2016.

El-Anwar, M. W.; Sweed, A. H. \& Abdulmonaem, G. Mental Foramen relation to mandibular fracture. J. Craniofac. Surg., 27(8):e743-5, 2016.

Fuentes, R.; Cantin, M.; Navarro, P.; Borie, E.; Beltrán, V. \& Bucchi, C. Caracterización de estructuras anatómicas mediante radiografías panorámicas: El Foramen Mental. Int. J. Morphol., 32(4):1423-9, 2014.

Gangotri, S.; Patni, V. M. \& Sathwane, R. S. Radiographic determination of position and symmetry of Mental Foramen in central Indian population. J. Indian Acad. Oral. Med. Radiol., 23(2):101-3, 2011.

Gungor, E.; Aglarci, O. S.; Unal, M.; Dogan, M. S. \& Guven, S. Evaluation of Mental Foramen location in the 10-70 years age range using conebeam computed tomography. Niger. J. Clin. Pract., 20(1):88-92, 2017.

Haghanifar, S. \& Rokouei, M. Radiographic evaluation of the Mental Foramen in a selected Iranian population. Indian J. Dent. Res., 20(2):1502, 2009.

Moiseiwitsch, J. R. Position of the Mental Foramen in a North American, white population. Oral. Surg. Oral. Med. Oral. Pathol. Oral. Radiol. Endod., 85(4):457-60, 1998.

Mohamed, A.; Nataraj, K.; Mathew, V. B.; Varma, B.; Mohamed, S.; Valappila, N. J. \& Meena, A.S. Location of Mental Foramen using digital panoramic radiography. J. Forensic Dent. Sci., 8(2):79-82, 2016.

Ngeow, W. C. \& Yuzawati, Y. The location of the Mental Foramen in a selected Malay population. J. Oral. Sci., 45(3):171-5, 2003.

Pyun, J. H.; Lim, Y. J.; Kim, M. J.; Ahn, S. J. \& Kim, J. Position of the Mental Foramen on panoramic radiographs and its relation to the horizontal course of the mandibular canal: a computed tomographic analysis. Clin. Oral. Implants. Res., 24(8):890-5, 2013.

Shah, P.P.; Parikh, K. K.; Shah, M. J. \& Khan, F. Radiographic study of Mental Foramen in a selected Indian population in Kheda district, Gujarat. J. Indian Acad. Oral. Med. Radiol., 25(1):13-7, 2013.

Shibli, J. A.; Martins, M. C.; Loffredo, L. C. \& Scaf, G. Detection of the Mandibular Canal and the Mental Foramen in panoramic radiographs: intraexaminer agreement. J. Oral. Implantol., 38(1):27-31, 2012.

Thakare, S.; Mhapuskar, A.; Hiremutt, D.; Giroh, V. R.; Kalyanpur, K. \& Alpana, K. R. Evaluation of the position of Mental Foramen for clinical and forensic significance in terms of gender in dentate subjects by digital panoramic radiographs. J. Contemp. Dent. Pract., 17(9):762-8, 2016.
Voljevica, A.; Talovic, E.; Hasanovic, A. Morphological and morphometric analysis of the shape, position, number and size of Mental Foramen on human mandibles. Acta. Med. Acad., 44(1):31-8, 2015.

Von Arx, T.; Friedli, M.; Sendi, P.; Lozanoff, S.; Bornstein, M. M. Location and dimensions of the Mental Foramen: a radiographic analysis by using Cone-Beam computed tomography. J. Endod., 39(12):1522-8, 2013.

\author{
Corresponding author: \\ Dr. Ramón Fuentes Fernández \\ Director \\ Research Center in Dental Sciences (CICO) \\ Dental School, Universidad de La Frontera \\ Av. Francisco Salazar 01145 \\ Box 54-D \\ Temuco \\ CHILE
}

Email: ramon.fuentes@ufrontera.cl

Received: 08-06-2017

Accepted: 13-09-2017 